\title{
ИНОСТРАННЫЙ КАПИТАЛ И ПРОБЛЕМЫ ИСПОЛЬЗОВАНИЯ ТРУДОВЫХ РЕСУРСОВ СЕЛЬСКОГО ХОЗЯЙСТВА В СТРАНАХ ЗАПАДНОЙ АФРИКИ
}

Аннотация. С учетом характера производственных отношений сельского хозяйства стран Западной Африки, выражающегося в том, что иностранный и национальный частный капитал, а также госсектор функиионируют в основном в сфере реализации (скупочные, сбытовые, снабженческие и кредитные организации), автор особое внимание уделяет анализу вторичных производственных отночений, которые, по его мнению, главным образом и порождают уменьшение спроса на сельскохозяйственную рабочую силуАвтором анализируются и особые направления аграрной эволюции на основе привлечения иностранного капитала («зеленая революиия》) как сельскохозяйственные поселения (фермерские поселения, многочелевые кооперативные общества), крупные механизированные фермы, кооперативы, охватываюшие, главным образом, сферу обращения, которые по мнению автора снижают трудоабсорбирующие возможности аграрного сектора. Автор считает, что регулирование деятельности транснациональных корпораций в современных условиях осуществляется надгосударственными международными политическими институтами, а влияние суверенных государств на сочиально-экономические прочессы в обществе идет на убыль. Автор утверждает, что важным составным элементом нацииональной стратегии развития должна стать долгосрочная политика государства в области внешнеэкономических отношений.Автор также утверждает, что сегодня экономический обмен не только неотделим от таких вопросов, как секторальное распределение производительных возможностей, структура системы потребления и приоритет, который необходимо отдать производству материальных благ, но и тесно связан с нерациональным использованием естественных и людских ресурсов. Поэтому, считает автор, до тех пор пока сельское хозяйство стран Западной Африки будет находиться на начальном этапе развития капитализма (утверждение капитализма в сфере обращения), торговый обмен промышленно развитых стран с африканскими будет являться определяюшим фактором в существовании безработищь и неполной занятости трудовых ресурсов сельского хозяйства

Ключевые слова: иностранный капитал, Организация Объединённых Наций, Международная организация труда, ЮНКТАД, прямые инвестищии, транснациональные корпорации, трудоспособное население, неполная занятость, «зеленая револющия», страны Западной Африки.

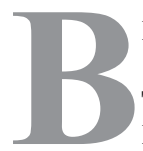

международном сообществе последнее десятилетие ведется обсуждение вопросов, касающихся «ответственного инвестирования», «корпоративной социаль- ной ответственности» со стороны международных корпораций. Важными ориентирами для определения и применения основополагающих норм «корпоративной социальной 


\section{Тренды и управление - №4(4) •2013}

ответственности» являются стандарты $\mathrm{OOH}^{1}$, $\mathrm{MOT}^{2}$ и ОЭСР ${ }^{3}$. В частности, В 2010 году лидеры «двадцатки» рекомендовали странам и транснациональным компаниям (ТНК) поддерживать принципы «ответственного инвестирования» в сельском хозяйстве развивающихся стран, разработанные Конференцией $\mathrm{OOH} \mathrm{по} \mathrm{торговле} \mathrm{и} \mathrm{развитию} \mathrm{(ЮНКТАД),}$

\footnotetext{
${ }^{1}$ Организация Объединённых Наций $(\mathrm{OOH})$ - международная организация, созданная для поддержания и укрепления международного мира и безопасности, развития сотрудничества между государствами.

${ }^{2}$ Международная организация труда (МOT) - специализированное учреждение $\mathrm{OOH}$, международная организация, занимающаяся вопросами регулирования трудовых отношений. На 2012 год участниками МОТ являются 185 государств. С 1920 года штаб-квартира Организации - Международного бюро труда, находится в Женеве. Тексты Конвенций и Рекомендаций МОТ на русском, английском, французском, испанском, китайском, немецком, португальском, арабском языках собраны в базе данных международных трудовых стандартов МОТ. МОТ не может принуждать к исполнению даже ратифицированных Конвенций. Тем не менее, существуют механизмы контроля МОТ за исполнением Конвенций и Рекомендаций, основная суть которых заключается в исследовании обстоятельств предполагаемых нарушений трудовых прав и придание им международной огласки в случае длительного игнорирования замечаний МОТ государством-участником. Этот контроль осуществляется Комитетом экспертов МОТ по применению Конвенций и Рекомендаций, Комитетом Административного Совета по свободе объединения и Комитетом Конференции по применению Конвенций и Рекомендаций.
}

${ }^{3}$ Организация экономического сотрудничества и развития (ОЭСР) - международная экономическая организация развитых стран, признающих принципы представительной демократии и свободной рыночной экономики. ОЭСР осуществляет обширную аналитическую работу, вырабатывает рекомендации для стран-членов и служит платформой для организации многосторонних переговоров по экономическим проблемам. Значительная доля деятельности ОЭСР связана с противодействием отмыванию денег, уходу от налогов, коррупции и взяточничеству. При участии ОЭСР были выработаны некоторые механизмы, призванные положить конец практике создания рядом государств так называемых «налоговых оазисов».
Всемирным банком, Международным фондом сельскохозяйственного развития (МФСР) и Продовольственной и сельскохозяйственной организацией ООН (ФАО $)^{4}$.

В современных условиях способы организации международного производства, направленные на углубление интеграции развивающихся стран в глобальные производственно-сбытовые цепочки, выходят за пределы прямых портфельных инвестиций (ПИИ), т.е. не связаны с участием в капитале (СНУК). Трансграничная деятельность на базе СНУК разрабатывалась международными организациями в последнее десятилетие именно для развивающихся стран и стран с переходной экономикой. Речь идет о таких типах договорных отношениях как подрядное промышленное и сельскохозяйственное производство, перевод на внешний подряд (аутсорсинг) услуг, франшизинг и лицензирование. Не связанные с приобретением акций формы типичны для гостиничного и ресторанного бизнеса, аренды автомобилей, розничной торговли, бухучета, правовых и других профессиональных услуг. С одной стороны, подобные формы инвестиций, продолжают открывать перед африканскими странами новые возможности для интеграции в глобальную экономику. С другой стороны, ТНК в итоге контролируют на территории принимающей страны не только сферу производства, но и сферы реализации продукта и услуг, а занятость в подрядном промышленном и сельскохозяйственном производстве может носить сильно выраженный циклический характер и может быть сведена на нет.

Огромная по своим масштабам армия безработных и неполностью занятых - наиболее существенная характеристика использования

\footnotetext{
${ }^{4}$ Более подробно см.: доклад о мировых инвестициях, 2011 год. Конференция ООН по торговле и развитию. ООН, Нью-Йорк и Женева, 2011 г.: www.un.org/ru/ development/surveys/docs/investments2011.pdf
} 
трудовых ресурсов сельского хозяйства стран Западной Африки. Возникновение данной проблемы порождено глубокой деформацией экономики как на уровне производительных сил, так и в рамках производственных отношений.

В африканских странах аграрное перенаселение имеет ряд существенных особенностей, главная из которых заключается в том, что оно порождается современными формами ведения хозяйства не так, как в метрополии. Если в промышленно развитых странах причиной безработицы является влияние современного этапа НТП основанного на массовом внедрении микроэлектроники и микропроцессоров, то факторы выталкивания рабочей силы из сельского хозяйства стран Западной Африки обусловливаются в значительной степени процессами в сфере реализации, т.е. вторичные производственные отношения воздействуют на соединение рабочей силы со средствами производства.

В отличие от стран Восточной Африки, где европейский капитал, выделившись из кругооборота промышленного капитала метрополии, утвердился в производительных отраслях сельского хозяйства, в странах Западной Африки он обосновался в виде ссудного и торгового капитала, т.е. иностранный капитал, проникая в сельское хозяйство на периферии, утверждается в сфере реализации (сбытовые и снабженческие кооперативы, скупочные и кредитные организации), в низших своих формах.

Преследуемая цель промышленно развитых стран - решение аграрного вопроса на основе современных форм ведения хозяйства при одновременном сохранении в «резерватах» традиционных форм хозяйства - объясняется сохраняющейся возможностью скупать продукцию сельских производителей стран Западной Африки по низким ценам. Поэтому, в целях содействия росту накопления ссудного и торгового капитала метрополии выгодно осуществлять консервацию исторически древнейших и допотопных форм хозяйства на периферии ${ }^{1}$.

В свою очередь, ростовщический и купеческий капитал стран Западной Африки, обладая слабым накоплением капитала и не имея возможности конкурировать с ссудным и торговым капиталом метрополии, не способствует появлению благоприятных условий для организации производства в сельском хозяйстве. По своему образу действий он продолжает участвовать в распределении и перераспределении «прибавочного», а также «необходимого» продукта. Обоснование европейского капитала и африканской буржуазии в непроизводительных отраслях экономики проявляется в том, что наиболее распространенная форма их взаимоотношений с сельскими производителями осуществляется через скупочные, сбытовые и снабженческие кооперативы и кредитные организации.

Сохранение западным капиталом, и прежде всего ТНК, многих командных позиций в экономике стран Западной Африки, дает возможность контролировать иностранному капиталу, как правило, почти все посреднические операции во внешней торговле - транспортировку, страхование, складирование, сбыт. Например, сбыт тропического продовольствия стран Западной Африки, а также зерна, каучука и пр. идет через товарные биржи в Нью-Йорке, Лондоне и Роттердаме, т.е. вне контроля африканских стран. В современных условиях через руки действуюших ТНК проходит 50-60\% всей торговли данного региона сахаром, 70-75\% бананами, рисом, каучуком, 85-90\% какао, чаем, кофе, табаком, хлопком.

\footnotetext{
${ }^{1}$ Более подробно о некоторых аспектах развития сельского хозяйства в странах Африки см.: Крылов В.В. Некоторые аспекты аграрного развития Африки // Азия и Африка сегодня. 1981. № 3. С. 29-33; Крылов В. В. Трудовые ресурсы и занятость в Африке // Азия и Африка сегодня. 1979. № 8. С. 39-43.
} 


\section{Тренды и управление - №4(4)• 2013}

Это ведет к массовому вывозу прибылей ТНК, и сохранению ими посреднических позиций между непосредственными производителями африканских стран и потребителями в развитых странах.

Более того, значительная доля экспорта и импорта, в современных условиях, в мировом хозяйстве приходится на долю продукции, реализуемой между филиалами ТНК.

Поскольку товары и услуги, участвующие во внутрикорпорационной торговле, не являются предметом так называемых сделок «на стороне», (т.е. сделок по рыночным ценам с фирмами, не являющимися филиалами), их цены определяются не рыночным механизмом, а самими корпорациями. Передаточные цены фирмы должны удовлетворять различным требованиям и при определении их уровня учитывается ряд факторов, включая тарифы импортирующей страны, абсолютные и дифференциальные налоговые ставки, фактические или предполагаемые различия в валютных курсах, политика правительства в области платы за пользование и в области перевода платежей, необходимость удовлетворять акционеров как в стране базирования, так и принимающих странах и многие другие факторы. В передаточные цены также может входить платеж за часть общих накладных расходов корпораций, значительную долю которых несет основная фирма.

Подобная практика предполагает огромный простор для установления трансфертных цен и уязвимость экономики принимающих стран по отношению к политике, осуществляемой иностранными государствами или корпорациями.

В свою очередь, экономическая политика государств стран Западной Африки, в значительной степени приспосабливается к деятельности ТНК в области рыночных отношений, Так, например, установление рыночных цен и налогов на сельскохозяйственную продук- цию со стороны административно-хозяйственных учреждений Нигерии - самая распространенная форма взаимоотношений между сельскими производителями, с одной стороны, частными и государственными учреждениями, с другой. Самая высокая доля этих взаимоотношений падает на систему сбыта продукции так называемых «внесенных в список сельскохозяйственных культур», которые, в свою очередь, являются исключительно экспортными культурами и чье производство контролируется федеральным Министерством по сбыту и торговым операциям. К таким культурам относятся: какао, земляной орех, хлопок, каучук, пальмовое масло, семя-бени, кофе, копра. Кроме того, Нигерийская компания по сбыту (N.P.M.C.) контролирует экспорт сельскохозяйственных культур и является структурным подразделением федерального Министерства по сбыту и торговым операциям. Эта организация принимает сортированный продукт от штатных министерств и экспортирует их в другие страны.

Подавление мелкого производства осуществляется на основе принудительного ценообразования. Районы, специализирующиеся на выращивании экспортных культур резервируются государством с целью продажи продукции только через кооперативы. Скупка товарной продукции у производителей осуществляется на основе государственных цен, которые как правило ниже цен свободного рынка. Таким образом, государство устанавливает монополию в сфере реализации товарной продукции, а кооперативы являются инструментом накопления капитала методами внеэкономического принуждения. Капитализирующий сектор производства овладевает прочными позициями в сельском хозяйстве через функционирование государственного механизма закупочных цен, существования государственной собственности (создание государством инфраструктуры для капитализирующего сектора, 
часть средств производства, используемых кооперативом, принадлежат государству). Так как соучастником преобразований в деревне является государство, то одновременно оно является как бы посредником во взаимоотношениях между деревней освободившихся стран и бывшими метрополиями ${ }^{1}$. Именно в руках государства находится жизненная артерия деревни, именно государство противодействует или отказывается от противодействия политики международных монополий, тем самым способствуя процессам воспроизводства мировым капиталом отношений зависимости. Государство берет под свою опеку деревню, пытаясь наладить связь между подразделениями экономики, относящихся к различным укладным формам. Поэтому изъятие продукта у сельских жителей может осуществляться в развивающихся странах не непосредственно через сельскую элиту, но и через государство. Сельским производителям Нигерии в результате существования многоступенчатой системы по реализации продукции достается только 38\% стоимости проданных товаров на международном рынке.

Подобные экономические формы взаимоотношений между субъектами рынка в африканской деревне усиливают негативные аспекты использования трудовых ресурсов, а именно, увеличивают армию безработных и неполностью занятых в сельском хозяйстве.

Участие сельского производителя в воспроизводственном процессе зависит от двух факторов: какое количество жизненных средств у него вынуждено изымают и в каком количестве он может получать необходимые ему предметы потребления. Но экономико-географические, социальные условия, сложности реализации продукта для сельских производителей не идентичны, поэтому повышение про-

\footnotetext{
${ }^{1}$ См.: Следзевский И. В. Формирование социально-эко-
} номической структуры Нигерии. М., 1984. С. 300. изводительности труда, удержание хозяйства с его примитивными орудиями труда остаются возможными лишь для меньшинства крестьян. И если сельский производитель находит выгодным расширить свои посевы сверх собственной потребности, то причина этого редкого явления - почти случайное нахождение канала реализации продукта. Большая часть сельского населения в поисках средств существования находит выгодным наем на отхожих промыслах, в фермерских хозяйствах (с сохранением своего натурально-хозяйственного или полунатурального надела, где иногда используется чужой труд). Это происходит потому, что из-за монополии на сбытовые операции землевладельцев, ростовщиков, государства и иностранного капитала производители лишены возможности сбывать свою продукцию в сколько-нибудь существенном объеме и получать необходимые им денежные средства.

Следует также особо подчеркнуть, что после завоевания странами Западной Африки политической независимости переориентация экспортной направленности этих стран (поставка на внешний рынок минерального сырья) усиливает такие тенденции в сельском хозяйстве как сокращение располагаемого времени для производства продуктов, необходимых производителю с целью удовлетворения его физических потребностей, и увеличение рабочего времени сельского производителя в чужом хозяйстве. Следствие этого - все более частая прикупка им необходимых продуктов. Если на данной ступени развития товарного производства прикупка продуктов становится необходимостью для производителей, то каждые последующие изменения в формах зависимости сельского хозяйства периферии от метрополии через каналы внешнеторговых операций сделают этот акт еще более обязательным, а конкуренция повысивших культуру зажиточных землевладельцев в результате развития капиталистических отношений в де- 


\section{Тренды и управление - №4(4)• 2013}

ревне неминуемо экспроприирует сельского производителя до конца, «обратив из пролетария, прикрепленного к земле, в пролетария, свободного как птица».

В современных условиях монополия развитых стран и государств Западной Африки в сфере реализации как никогда влияет на изменение и объективных условий занятости резко начала снижаться обеспеченность населения сельской местности земельными ресурсами. Это объясняется тем, что наделы домочадцев имеют тенденцию в условиях развития капиталистических отношений к сокращению в пользу главы семьи. Вследствие уменьшения наделов и увеличения платежей, сельские производители перебивают работу друг у друга, что сопровождается выталкиванием некоторой их части из сферы производства. Крупный же собственник обходится относительно меньшим числом рабочих рук. Крупным землевладельцам выгодно стало сдавать землю в аренду, так как они берут себе львиную долю продукта, производимого на их земле, а «пищевая площадь» доступная крестьянину уменьшается вследствие роста платежей: ведь население не прямо обращает на себя добытые им продукты «естественного плодородия», оно «делится» ими с частными предпринимателями, государством. Следовательно, наделы перестают быть источником удовлетворения нужд производителя. С распространением аренды и развитием товарно-денежных отношений родоплеменная верхушка получила новые источники обогащения, экономической основой которого является право вождей распоряжаться общинной землей, что становится одной из причин возникновения такого феномена, как «нужда в земле», даже для те стран, где имеется достаточное количество земельных угодий. Так, например, во многих районах Нигерии наличие богатых земельных ресурсов сочетается с низкой плотностью населения. К ним относятся большая часть редкозаселенных равнин северо-восточных и северо-западных штатов, где земля пригодна для возделывания арахиса и других культур и где есть все условия для развития многоотраслевых хозяйств. К этому типу относятся и районы провинции Нигер, и северные части штата Квара, где можно было бы выращивать в большом количестве продовольственные культуры на внутренний рынок. Это касается и обширных территорий некоторых районов западных штатов Нигерии, например, провинции Ойо и Ийебу, некоторых районов штата Лагос (Эпе), равнины Нике близ Энугу. В перечисленных районах обширные зоны плодородных земель и лесов остаются неосвоенными. Существуют также окраинные зоны с достаточно большим земельным потенциалом.

В свою очередь, «зеленая революция» (введение сельскохозяйственных поселений, кооперативов, крупных механизированных ферм, мелкой промышленности, ремесленно-кустарного производства), хотя и должна способствовать совершенствованию орудий труда, не относится к главному фактору вытеснения рабочей силы из сельского хозяйства, так как из-за мизерности доходов или вообще их полного отсутствия лишь незначительная часть сельских производителей может использовать инновации. Крупные же хозяйства пока еще не играют сколько-нибудь значительной роли в обеспечении занятости ввиду своей малочисленности, а также более высокой механизации, снижающей трудоабсорбирующие возможности. «Зеленая революция» в данной форме влияет прежде всего на формирование новой системы потребностей. Но не все социальные группы людей в африканской деревне могут интенсивно формировать новую систему потребностей. Традиционно личное потребление выступает в деревне зачастую в форме коллективного потребления. «Зеленая революция» как раз и стимулирует процесс поиска новой работы с целью удовлетворения новых потреб- 
ностей. В этом состоит важнейшее позитивное достижение «зеленой революции».

Для быстрого развития «зеленой революции» необходимо, чтобы производство продуктов в африканских странах соответствовало бы платежеспособному спросу сельских жителей с тем, чтобы устранить имеющиеся диспропорции в продовольственном обеспечении. Но даже если это соответствие и будет достигнуто, то появятся трудности в реализации произведенной продукции. И этот закон обратной связи срабатывает тем быстрее, чем сильнее разовьется производство в очагах «зеленой революции».

В современных условиях проблема реализации осложнена усиливающейся дестабилизацией экономики промышленно развитых стран (валютный, финансовый, энергетический кризисы, глобальные рецессии). Поэтому большое значение в данной ситуации для стран Западной Африки имеет способность приспосабливаться к изменяющемуся международному рынку. Приспособление должно осуществляться путем изменения условий во внутренней и внешней торговле. Кроме того, в своей политике по обеспечению занятости в сельском хозяйстве правительствам стран Западной Африки следует сделать большой упор на производство продукции в мелких хозяйствах, а не плантациях, ибо первый случай предпочтительнее в точки зрения вовлечения трудовых ресурсов сельского населения в трудовую деятельность, а именно, на производство товарных, экспортных культур, так как это также увеличивает потребность в рабочей силе. Эти коррективы неизбежно отражаются на распределении дохода сельских производителей и их занятости.

Интенсификация национальной экономики проводится в Нигерии и других странах Западной Африки через развитие таких основных отраслей промышленности как обрабатывающая и добывающая, через укрепление строительства и сельского хозяйства и призвана одновременно решить несколько задач: обеспечить экономическую самостоятельность страны, заложить материальные основы преобразования сельского хозяйства, изыскать пути для постепенного рассасывания городской безработицы и аграрного перенаселения.

Распределение трудовых ресурсов между отраслями народного хозяйства определяется относительным переливом рабочей силы из сельского и лесного хозяйства в промышленность, строительство, сферу обслуживания. В течение 1960-2000 годов среднегодовые темпы прироста городско населения стран Западной Африки находились на уровне 5,4\%. Согласно оценкам, доля городского населения в его общей численности выросла в пределах указанного периода в этих странах с 16,6\% до 42,5\%. Если в 1990 г. двети трети населения Нигерии проживало в деревне, то уровень урбанизации уже в 2010 г. составил 49,8\% и к 2030 г. по оценкам программы UN -HABITAT более $60 \%$ населения будет проживать в городах ${ }^{1}$. По количеству занятого населения впереди стоят отрасли легкой промышленности, при этом в пищевой и текстильной - почти 70\% общей численности работающих в промышленности данного региона. Одновременно, в Нигерии на долю легкой промышленности приходилось 2/3 всего объема прироста промышленной продукции. Но сравнительно высокие темпы роста отраслей обрабатывающей промышленности не приводят в данной стране, однако, к увеличению их удельного веса в ВВП. Наибольший рост промышленной продукции отмечался, как правило, на крупных предприятиях

Согласно существующему подходу к решению проблем экономического роста при

${ }^{1}$ The State of African Cities 2012/2013: Prosperity of Cities. UN - HABITAT. United Nations Human settlements programme. P. 145. 
создании новых современных предприятий (их обычно принято относить к «организованному сектору) приоритет отводится капиталу с высоким органическим строением. Использование капиталоемкой техники заметно снижает потребности производства в живом труде, отсюда, соответственно, и ограниченный спрос на дополнительные руки. В Нигерии, например, за период с 1986 по 1990 год на предприятиях «организованного сектора» предполагалось создать только $12 \%$ общего числа новых рабочих мест.

Подобное относительное сокращение потребностей производства в живом труде могло бы перекрыться увеличением спроса на рабочую силу, который обычно идет параллельно углублению общественного разделения труда, появлению новых отраслей экономики. Однако, темпы развития несельскохозяйственных отраслей экономики заметно отстают в африканских странах от темпов роста трудовых ресурсов городских районов ${ }^{1}$. Несмотря на то, что занятость городского населения, практически, везде выросла, уровень безработицы по-прежнему остается здесь высоким. По оценкам MOT, в 2005 году безработные составляли 10\%, неполностью занятые - $25 \%$ общей численности экономически активного населения городских районов стран Западной Африки.

Своего рода предохранительного клапана играет в городе «неорганизованный сектор», который включает в себя примитивное мелкое и ремесленное производство и традиционную сферу услуг.

Занятость в «неорганизованном секторе», практически везде, имеет тенденцию к росту.

\footnotetext{
${ }^{1}$ Более подробно см.: Абрамова И.О. Урбанизация в Африке. Двигатель или тормоз экономического роста // Азия и Африка сегодня. 2013. № 8. С. 4; Абрамова И.О. Африканская миграция: опыт системного анализа. М., 2009. С. 67; Economic Report on Africa, 2010.U.N. ECA. N.Y., 2010. P. 58; African Economic Outlook 2010.OECD/ADB. Addis Ababa. 2010. P. 35.
}

Так, обследования, проведенные по линии МOT в середине 90-х годов, показали, что в течение пяти лет, предшествовавших им, во Фритауне было создано - 59\% новых предприятий, в Кумаси - 52\%, в Лагосе $66 \%$, в Бамако - 55\%, в Нуакшоте - $81 \%$. Низкий технический уровень производства, соответственно низкие требования, предъявляемые здесь к рабочей силе, облегчают возможность трудоустройства для малообразованной части населения африканских городов и, в первую очередь, мигрантов. Картина занятости в «неорганизованном секторе» во многом является как бы зеркальным отражением состава аграрного перенаселения. Мигранты из сельской местности дают основное пополнение этому сектору. Так, в Лагосе 85\% лиц, возглавляющих здесь предприятия, были выходцами именно из сельских районов страны, причем стаж городской жизни не превышал 10 лет.

Хотя основным компонентом этого роста явилось расширение традиционной сферы услуг, нельзя не отметить и появление в африканских городах современных отраслей обслуживания: ремонтные службы, туризм, гостиничное хозяйство.

Но и динамика занятости в «неорганизованном секторе» не всегда отражает действительный рост спроса на рабочую силу. Так, 87\% среди опрошенных в этом секторе во Фритауне были отнесены к категории полностью занятых, остальные - занятых частично.

Учитывая чрезвычайно низкий уровень производительности труда, можно предположить, что в значительных масштабах занятость носит здесь лишь формальный характер. Подобное искусственное разбухание сектора является вполне закономерным следствием сложившихся диспропорций между темпами роста численности трудовых ресурсов городских районов и возможностями обеспечить это пополнение рабочими местами. 
В настоящее время мероприятия по рассасыванию безработицы становятся важнейшей задачей экономической политики молодых государств. Государственный сектор становится тем орудием, с помощью которого появляется возможность проводить целенаправленную политику по более рациональному использованию рабочей силы в сельском хозяйстве 1

Поиски и пути решения проблемы занятости, на наш взгляд, должны быть связаны с общим развитием национальной экономики, a, следовательно, должны являться интегральной частью этого процесса. Стратегия политики занятости - вторична по отношению к политике индустриализации - магистральному пути ликвидации недоиспользования трудовых ресурсов. Поэтому пути и средства решения проблемы занятости можно разделить на основные и вспомогательные. Основные пути: индустриализация национального хозяйства, кооперирование в сельском хозяйстве, государственные организационно-административные меры, вспомогательные: мелкая промышленность, ремесленно-кустарное производство, сельскохозяйственные поселения и т.п. Такое деление до некоторой степени условно, потому, что в исторической ретроспективе все они представляются важными, необходимыми и для своего времени оправданными, даже если некоторые из них не получили должного развития. Но необходимость такого разграничения, особенно в связи с предпринимаемыми ныне усилиями в странах Западной Африки, не вызывает сомнения: только в этом случае становится вполне ясной относительная значимость отдельных направлений экономической политики государства и эффективность их использования. Кроме того, это не означает, что вспомогательные меры - второстепенные. Такое истолкование было бы ошибкой. Они

\footnotetext{
${ }^{1}$ См.: Мельянцев В.А. Развивающиеся страны в эпоху
} перемен. М., 2009. С. 163. играют свою определенную роль, и эта роль во многих случаях может быть существенной, Но делать главный упор на вспомогательных мероприятиях в противовес основным было бы, по-видимому, гораздо большей ошибкой.

Проведенное исследование дает возможность автору сделать следующие выводы.

Регулирование деятельности транснациональных корпораций в современных условиях осуществляется надгосударственными международными политическими институтами, то влияние суверенных государств на социально-экономические процессы в обществе идет на убыль. Решение проблемы собственности на средства производства, в частности иностранной и национальной собственности, диктует соответственное отношение к иностранному капиталу. Важным составным элементом национальной стратегии развития должна стать долгосрочная политика государства в области внешнеэкономических отношений.

Экономический обмен между метрополией и периферией уже давно не носит исключительно коммерческий характер, ни даже финансовый, хотя эти области весьма важны. Сегодня экономический обмен не только неотделим от таких вопросов, как секторальное распределение производительных возможностей, структура системы потребления и приоритет, который необходимо отдать производству материальных благ, но и тесно связан с нерациональным использованием естественных и людских ресурсов. Поэтому, до тех пор пока сельское хозяйство стран Западной Африки будет находиться на начальном этапе развития капитализма (утверждение капитализма в сфере обращения), торговый обмен промышленно развитых стран с африканскими будет являться определяющим фактором в существовании безработицы и неполной занятости трудовых ресурсов сельского хозяйства. 


\section{Библиография}

1. Абрамова И. О. Урбанизация в Африке. Двигатель или тормоз экономического роста // Азия и Африка сегодня. 2013. № 8;

2. Абрамова И.О. Африканская миграция: опыт системного анализа. М., 2009;

3. Крылов В.В. Некоторые аспекты аграрного развития Африки // Азия и Африка сегодня. 1981. № 3;

4. Крылов В.В. Трудовые ресурсы и занятость в Африке // Азия и Африка сегодня. 1979. № 8;

5. Мельянцев В.А. Развивающиеся страны в эпоху перемен. М., 2009;

6. Следзевский И.В. Формирование социальноэкономической структуры Нигерии. М., 1984;

7. African Economic Outlook 2010.OECD/ADB. Addis Ababa. 2010;

8. Economic Report on Africa, 2010.U.N. ECA. N.Y. 2010;

9. The State of African Cities 2012/2013: Prosperity of Cities. UN - HABITAT. United Nations Human settlements programme.

\section{References (transliterated)}

1. Abramova I. O. Urbanizatsiya v Afrike. Dvigatel» ili tormoz ekonomicheskogo rosta // Aziya i Afrika segodnya. 2013. № 8;

2. Abramova I. O. Afrikanskaya migratsiya: opyt sistemnogo analiza. M., 2009;

3. Krylov V. V. Nekotorye aspekty agrarnogo razvitiya Afriki // Aziya i Afrika segodnya. 1981. № 3;

4. Krylov V. V. Trudovye resursy i zanyatost» V Afrike // Aziya i Afrika segodnya. 1979. № 8;

5. Mel'yantsev V. A. Razvivayushchiesya strany v epokhu peremen. M., 2009;

6. Sledzevskii I. V. Formirovanie sotsial'noekonomicheskoi struktury Nigerii. M., 1984;

7. African Economic Outlook 2010.OECD/ADB. Addis Ababa. 2010;

8. Economic Report on Africa, 2010.U.N. ECA. N.Y. 2010;

9. The State of African Cities 2012/2013: Prosperity of Cities. UN - HABITAT. United Nations Human settlements programme. 